\title{
Cryopreservation of spermatozoa of indigenous stinging catfish, Heteropneustes fossilis (Bloch) for ex-situ conservation
}

\author{
MD. RAFIQUL ISLAM SARDER*, MD. ABUL KALAM AZAD, \\ K.M. SHAHRIAR NAZRUL ${ }^{1}$ AND MOHAMMAD RASHED ${ }^{2}$ \\ Dept. of Fisheries Biology \& Genetics, Bangladesh Agricultural University \\ Mymensingh 2202, Bangladesh \\ ${ }^{1}$ Department of Fisheries, Dhaka 1000, Bangladesh \\ ${ }^{2}$ Department of Fisheries Biology \& Genetics \\ Sher-e-Bangla Agricultural University, Dhaka 1207 \\ *E.mail: rafiqulsarder@yahoo.com
}

\begin{abstract}
An experiment was conducted to develop cryopreservation protocol for spermatozoa of stinging catfish, Heteropneustes fossilis and to use the cryopreserved sperm in its breeding trials. The activation of sperm motility at various concentrations of $\mathrm{NaCl}$ solution was tested and complete activation and inhibition of sperm were obtained at $0.4 \%$ and $0.9 \%$ to $1 \% \mathrm{NaCl}$ solution respectively. In toxicity test, sperms were incubated with DMSO, methanol and ethanol at 5, 10, and 15\% concentrations where DMSO and methanol produced better motility at 5 and $10 \%$ concentration with Alsever's solution and egg-yolk citrate at 5 and- 10 min incubation period. Three extenders- Alsever's solution, egg-yolk citrate and Ginsburg Fish Ringer solution and three cryoprotectants- DMSO, methanol and ethanol were used for cryopreservation of sperm, and among the diluents, Alsever's solution with 10\% DMSO showed best performance producing $77.50 \pm 3.22 \%$ post-thaw motility. On the other hand, egg-yolk citrate and Ginsburg Fish Ringer solution along with $10 \%$ DMSO produced $63.75 \pm 2.39 \%$ and $62.50 \pm 3.22 \%$ post-thaw motility, respectively. Sperm preserved with Alsever's solution plus $10 \%$ DMSO produced $52.5 \pm 3.34 \%$ and $38.0 \pm 2.39 \%$ fertilization and hatching, and those preserved with Alsever's solution plus $10 \%$ methanol produced $46.9 \pm 3.11 \%$ and $32.7 \pm 2.70 \%$ fertilization and hatching respectively. The fry produced using cryopreserved and fresh sperm grew well and no significant difference $(p>0.05)$ was found between two groups.
\end{abstract}

Keywords: Cryopreservation, Spermatozoa, H. fossilis, Breeding

\section{Introduction}

Heteropneustes fossilis (shing) is a popular indigenous catfish and have got many qualities that make it a perfect candidate for pond culture. They grow rapidly and attain marketable size within one growing season (Islam 1989). They have also high demand and market value. From nutritional point of view, shing is an excellent food fish. The protein of this fish is relatively of high digestibility having biological and growth promoting value for human consumption (Srivastava 1988). Being air-breathing, these fish can thrive in various adverse conditions and can easily be grown in shallow, small ponds and ditches and even in derelict water bodies. They breed in natural shallow waters during monsoon season usually after heavy shower when the adjoining area of ponds and other depressions get inundated. It is a voracious predator native to South-East Asia and has been introduced into many places for fish farming. $H$. fossilis has been described as a benthic, nocturnal, tactile omnivore that consumes detritus and opportunistically forages on large aquatic insects, tadpoles and fish. 
In spite of many advantages, not much attempt has been taken to promote breeding, genetic improvement and conservation of shing. Production and availability of quality seeds is the main obstacle for its culture. The demand of fry increased many fold as culture of shing has received special attention of many farmers in the recent time. To satisfy the increasing demand of farmers for fry, the species is being artificially bred in many private hatcheries but it encounters problems such as unavailability of wild broods, sacrificing male broods, and narrowing the genetic variability of broodstocks for captive rearing of small number of fish and their use in breeding. There are a few techniques available to conserve the genetic resources of $H$. fossilis and cryopreservation of gametes is considered as the most important and effective method. Cryopreservation of fish deals with cryobiology that relates to the long-term preservation and storage of biological material at very low temperature, usually at $-196^{\circ} \mathrm{C}$. As the biodiversity of this valuable fish has been reduced to a greater extent; it is the high time to apply cryopreservation technique to conserve the gene pool of $H$. fossilis. Therefore, the main objectives of this study were 1) to determine the suitable extenders and cryoprotectants and their combination, 2) to develop the protocols for fertilization of eggs using cryopreserved sperm, and 3) to study the effect of cryopreserved sperm on the growth of fry.

\section{Materials and Methods}

Brood collection, rearing, and conditioning. Brood fish of $H$. fossilis were collected from natural sources of Mymensingh region and reared in the ponds located besides the Fisheries Faculty building. Fish were fed with supplementary feed twice a day at the rate of $4-5 \%$ of body weight. Matured male fish were caught from the stocking pond about $6 \mathrm{~h}$ prior to hormone treatment and kept in cistern with proper aeration by continuous showering through PVC pipe.

Preparation of PG extract and injection and collection of milt. Required amount of PG was homogenized in a tissue homogenizer with small amount of distilled water; the solution was centrifuged for $5 \mathrm{~min}$ at $4000 \mathrm{rpm}$ and the supernatant was taken out in a $1 \mathrm{ml}$ hypodermic syringe. For inducing the fish, a single dose of PGE (pituitary gland extract) was given to both male and female fish. The doses of PGE were $65-75 \mathrm{mg} / \mathrm{kg}$ body weight for female and 4-6 $\mathrm{mg} / \mathrm{kg}$ body weight for male. The induced male broods were sacrificed, the testes were kept in a Petri dish along with extender and cut into small pieces. The milt was collected by a pipette and put in an eppendorf tube. The quality of sperm was examined by using a light microscope.

Expt.-I: Selection of suitable activation solution: Sperm collected from crushed testes was suspended in a suitable extender and kept on ice. A graded series of $\mathrm{NaCl}$ stock solution (from $0.1 \%$ to $1 \%$ ) was prepared by mixing $\mathrm{NaCl}$ salt with distilled water. About $1 \mu \mathrm{l}$ of sperm suspension was placed on a glass slide and $20 \mu \mathrm{l}$ of $\mathrm{NaCl}$ solution from the stock of graded series was added to activate the sperm. The motility of sperm was observed immediately under microscope and the percent of motility was recorded.

Expt.-II: Evaluation of toxicity of cryoprotectant to sperm: The toxicity was evaluated following the method of Yang et al. (2007) and Sarder et al. (2013). Milt was diluted at a ratio of 1:4 for egg-yolk citrate and 1:9 for Alsever's solution and Ginsburg Fish Ringer solution. The cryoprotectants (DMSO, Methanol and Ethanol) were mixed with the milt to make the final concentration of cryoprotectant at 5,10 and $15 \%$. The mixture was kept on ice. The toxicity of 
these cryoprotectants was measured by monitoring the motility of sperm under microscope for a period of $45 \mathrm{~min}$ at $5 \mathrm{~min}$ interval.

Expt.-III: Determination of suitable extenders, cryoprotectants and their combination: Three extenders such as Alsever's solution, egg-yolk citrate and Ginsburg Fish Ringer solution and three cryoprotectants such as DMSO, methanol and ethanol were used for cryopreservation of sperm. Diluents were prepared by adding $10 \%$ cryoprotectant to $90 \%$ extender (v/v). For each diluent at least three replications were maintained to get minimum error. After collection of milt sample, the following procedures were maintained.

Evaluation of sperm quality: For checking quality of the sperm, 1-2 $\mu \mathrm{l}$ of milt was placed on a slide and 50-100 $\mu \mathrm{l}$ of distilled water was added. The motility of the sperm was observed under a microscope. Milt with more than $80 \%$ motile sperm was used for cryopreservation.

Freezing and thawing of milt. Collected milt samples were diluted with diluent (extender plus cryoprotectant) at a ratio of 1:4 for egg-yolk citrate and 1:9 for Alsever's solution and Ginsburg Fish Ringer solution. The milt was equilibrated for $10 \mathrm{~min}$ and during equilibration $0.23 \mathrm{ml}$ diluted milt was drawn into each $0.25 \mathrm{ml}$ plastic French straws (Minitüb System, Minitüb, Tiefenbach, Germany) by a micropipette. The free ends of the straws were manually sealed with the help of a heated crucible tongs. The motility of sperm in all the samples was examined before addition of cryoprotectant and again just before initiation of freezing as equilibration motility. The sealed plastic straws containing diluted milt were loaded into the cryochamber. A Computer controlled freezer (CL-3300) was used to freeze the sample using the one-step freezing protocol, where milt sample was cooled from the ambient temperature $20^{\circ} \mathrm{C}$ to $-80^{\circ} \mathrm{C}$ at a decreasing rate of $10^{\circ} \mathrm{C}$ per min. After freezing, the samples were transferred into liquid nitrogen $\left(-196^{\circ} \mathrm{C}\right)$ for storage. For observing the post-thaw motility of sperm, frozen straws were retrieved from the $\mathrm{LN}_{2}$ container using a tweezer and thawed at room temperature for 30-40 sec. One to $2 \mu \mathrm{l}$ of thawed milt was taken onto a glass slide and 150-200 $\mu \mathrm{l}$ of distilled water was added to activate the sperm. The motility of sperm was assessed under a binocular microscope.

Expt.- IV: Effects of cryopreserved spermatozoa on fertilization and hatching rates: Eggs were collected from induced female broods by stripping into a plastic bowl immediately after ovulation and divided into 3 batches of approximately 500-600 eggs each. Two batches of eggs were fertilized with cryopreserved sperm preserved with two different diluents and one batch with fresh sperm as control. The frozen straws, after thawing at room temperature for about 30$60 \mathrm{sec}$, were cut at both ends and mixed with eggs. Each batch of eggs with a replication was fertilized with $5 \times 230 \mu \mathrm{l}$ of cryopreserved milt where each straw contained $230 \mu \mathrm{l}$ milt. For control, adequate amount of fresh milt was used. The fertilized eggs were transferred into incubation tray and continuous water shower was provided over the tray to ensure additional dissolved oxygen. After 1-2 hr of fertilization, some eggs were collected from tray and the progress of cell division was observed under microscope. After 23-28 hr of fertilization when the eggs hatched out, hatchlings were counted and transferred to plastic bowls for rearing.

Expt.- V: Effects of cryopreserved spermatozoa on growth and survival of fry: After absorption of yolk sac when the hatchlings started feeding, hard boiled hen egg-yolk was supplied. Chopped Tubifex and plankton collected from ponds were also provided to the fry. For 
comparing the growth between the fry produced with cryopreserved sperm and fresh sperm, 20 fry (10 days-old) of each group were stocked to each glass aquarium (50 inch x 30 inch x 28 inch) and reared them for eight weeks. The fries were fed twice a day with a supplemental feed comprising of fish meal $25 \%$, rice bran $25 \%$ and an egg. In addition, chopped Tubifex and plankton were also provided to the aquarium. The length and weight of fry were measured throughout the experimental period at seven days interval.

Statistical analyses: The effects of different extenders and cryoprotectants on equilibration and post-thaw motility of spermatozoa were analyzed with the help of MSTAT computer based software. Means were separated following Duncan's Multiple Range Test (DMRT) at 1\% and $5 \%$ level of significance. The effect of cryopreserved sperm on the fertilization and hatching rates of eggs were analyzed by a t-test. The data on growth of fry was analyzed by one-way analysis of variance (ANOVA) followed by Duncan's Multiple Range Test (DMRT) through SPSS computer-based software.

\section{Results}

Selection of suitable activation solution: The activation of motility of sperm tested at various concentrations of $\mathrm{NaCl}$ solution showed that the activation of sperm motility decreased with the increase of $\mathrm{NaCl}$ concentration. In case of Alsever's solution, the sperm motility in $0.1 \% \mathrm{NaCl}$ solution ( $48 \mathrm{mOsmol} / \mathrm{kg}$ ) was $90 \%$ which gradually reduced to $85 \%$ at $0.4 \% \mathrm{NaCl}$ solution (128 $\mathrm{mOsmol} / \mathrm{kg}$ ) and became 0 at $1 \% \mathrm{NaCl}$ solution $(319 \mathrm{mOsmol} / \mathrm{kg})$. The motility was more or less stable at $0.4 \% \mathrm{NaCl}$ solution (Fig. 1). In case of egg-yolk citrate and Ginsburg Fish Ringer, the motility of sperm in $0.1 \% \mathrm{NaCl}$ solution was about $85 \%$ and it remained same at $0.4 \% \mathrm{NaCl}$ and completely stopped at $0.9 \% \mathrm{NaCl}$ solution $(287 \mathrm{mOsmol} / \mathrm{kg})$. In both extenders, the motility of sperm was more or less stable at $0.4 \% \mathrm{NaCl}$ solution $(128 \mathrm{mOsmol} / \mathrm{kg})$ (Fig.1).

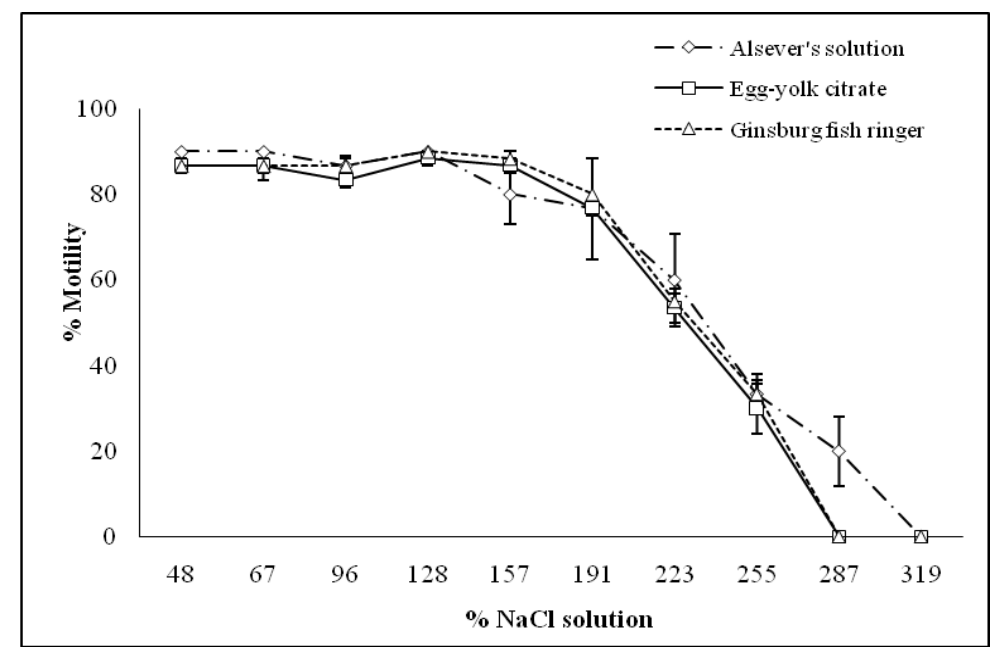

Fig. 1. Motility of sperm of $H$. fossilis in different osmolalities of $\mathrm{NaCl}$ solution. 
Evaluation of toxicity of cryoprotectant to sperm: The motility of fresh sperm before incubation with cryoprotectants was $80-95 \%$. The motility of sperm decreased with the increase of cryoprotectant concentration $(5,10$ and $15 \%$ ) and incubation time (5 to $45 \mathrm{~min}$ ) for DMSO, methanol and ethanol. Alsever's solution with 5\% DMSO produced $81 \pm 2 \%$ motility at 5 min incubation which reduced to $80 \pm 3 \%$ at $10 \mathrm{~min}$. DMSO at $10 \%$ concentration produced $80 \pm 2 \%$ motility at $5 \mathrm{~min}$ incubation that reduced to $75 \pm 3 \%$ at $10 \mathrm{~min}$. Methanol at $5 \%$ concentration showed $81 \pm 2 \%$ motility at $5 \mathrm{~min}$ and $78 \pm 2 \%$ motility at $10 \mathrm{~min}$ of incubation. At $10 \%$ concentration methanol produced $78 \pm 2 \%$ motility at 5 min incubation which dropped to $71 \pm 2 \%$ at $10 \mathrm{~min}$. Similarly, ethanol at 5 and $10 \%$ concentration produced $81-73 \%$ motility at 5 min incubation but it reduced to $78-68 \%$ at $10 \mathrm{~min}$ incubation (Table I).

Table I. Effects of different cryoprotectants on motility of sperm of $H$. fossilis

\begin{tabular}{|c|c|c|c|c|c|c|c|c|c|c|c|c|}
\hline \multirow{3}{*}{ 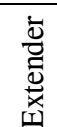 } & \multirow{3}{*}{\multicolumn{2}{|c|}{ Cryoprot. }} & \multicolumn{10}{|c|}{ Time (min) } \\
\hline & & & Initial & 5 & 10 & 15 & 20 & 25 & 30 & 35 & 40 & 45 \\
\hline & & & \multicolumn{10}{|c|}{ \% Motility } \\
\hline \multirow{9}{*}{ 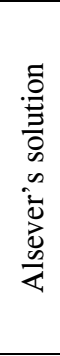 } & \multirow{9}{*}{ 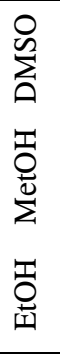 } & $5 \%$ & $86 \pm 1$ & $81 \pm 2$ & $80 \pm 3$ & $75 \pm 3$ & $70 \pm 3$ & $56 \pm 3$ & $45 \pm 3$ & $35 \pm 3$ & $21 \pm 4$ & $3 \pm 3$ \\
\hline & & $10 \%$ & $83 \pm 1$ & $80 \pm 2$ & $75 \pm 3$ & $63 \pm 1$ & $46 \pm 3$ & $40 \pm 3$ & $26 \pm 3$ & $18 \pm 2$ & $6 \pm 3$ & 0 \\
\hline & & $15 \%$ & $78 \pm 1$ & $73 \pm 2$ & $63 \pm 3$ & $46 \pm 3$ & $30 \pm 6$ & $13 \pm 3$ & $3 \pm 3$ & 0 & 0 & 0 \\
\hline & & $5 \%$ & $83 \pm 1$ & $81 \pm 2$ & $78 \pm 2$ & $71 \pm 1$ & $66 \pm 2$ & $56 \pm 4$ & $45 \pm 9$ & $33 \pm 3$ & $23 \pm 3$ & $6 \pm 3$ \\
\hline & & $10 \%$ & $80 \pm 0$ & $78 \pm 2$ & $71 \pm 2$ & $65 \pm 3$ & $63 \pm 3$ & $55 \pm 5$ & $43 \pm 9$ & $13 \pm 3$ & $3 \pm 3$ & 0 \\
\hline & & $15 \%$ & $80 \pm 0$ & $73 \pm 0$ & $68 \pm 5$ & $58 \pm 0$ & $48 \pm 0$ & $38 \pm 0$ & $25 \pm 0$ & 0 & 0 & 0 \\
\hline & & $5 \%$ & $81 \pm 1$ & $81 \pm 2$ & $78 \pm 2$ & $66 \pm 3$ & $56 \pm 6$ & $43 \pm 3$ & $33 \pm 3$ & $16 \pm 3$ & $6 \pm 3$ & 0 \\
\hline & & $10 \%$ & $81 \pm 5$ & $73 \pm 3$ & $68 \pm 5$ & $63 \pm 5$ & $48 \pm 10$ & $36 \pm 5$ & $16 \pm 5$ & $3 \pm 3$ & 0 & 0 \\
\hline & & $15 \%$ & $76 \pm 3$ & $66 \pm 3$ & $53 \pm 4$ & $36 \pm 3$ & $20 \pm 6$ & $10 \pm 6$ & 0 & 0 & 0 & 0 \\
\hline \multirow{9}{*}{ 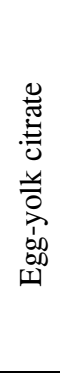 } & \multirow{9}{*}{ 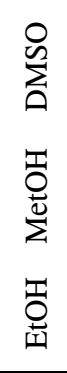 } & $5 \%$ & $81 \pm 1$ & $81 \pm 2$ & $76 \pm 2$ & $71 \pm 1$ & $66 \pm 2$ & $61 \pm 2$ & $46 \pm 3$ & $21 \pm 2$ & $3 \pm 3$ & 0 \\
\hline & & $10 \%$ & $81 \pm 1$ & $78 \pm 2$ & $73 \pm 2$ & $63 \pm 1$ & $53 \pm 1$ & $38 \pm 0$ & $21 \pm 0$ & $6 \pm 0$ & 0 & 0 \\
\hline & & $15 \%$ & $78 \pm 1$ & $71 \pm 2$ & $63 \pm 2$ & $56 \pm 1$ & $40 \pm 3$ & $23 \pm 3$ & $10 \pm 0$ & 0 & 0 & 0 \\
\hline & & $5 \%$ & $81 \pm 1$ & $81 \pm 2$ & $78 \pm 2$ & $71 \pm 1$ & $71 \pm 2$ & $61 \pm 2$ & $41 \pm 2$ & $13 \pm 3$ & 0 & 0 \\
\hline & & $10 \%$ & $78 \pm 1$ & $71 \pm 2$ & $63 \pm 1$ & $50 \pm 3$ & $43 \pm 3$ & $35 \pm 3$ & $20 \pm 3$ & $6 \pm 3$ & 0 & 0 \\
\hline & & $15 \%$ & $73 \pm 3$ & $58 \pm 4$ & $48 \pm 4$ & $41 \pm 4$ & $31 \pm 1$ & $21 \pm 2$ & $13 \pm 3$ & 0 & 0 & 0 \\
\hline & & $5 \%$ & $80 \pm 2$ & $78 \pm 1$ & $76 \pm 2$ & $71 \pm 1$ & $61 \pm 1$ & $51 \pm 2$ & $26 \pm 3$ & $16 \pm 3$ & 0 & 0 \\
\hline & & $10 \%$ & $75 \pm 3$ & $75 \pm 3$ & $70 \pm 3$ & $61 \pm 2$ & $53 \pm 1$ & $28 \pm 4$ & $18 \pm 4$ & $6 \pm 3$ & 0 & 0 \\
\hline & & $15 \%$ & $71 \pm 4$ & $68 \pm 3$ & $66 \pm 3$ & $55 \pm 3$ & $48 \pm 1$ & $15 \pm 3$ & 0 & 0 & 0 & 0 \\
\hline \multirow{9}{*}{ 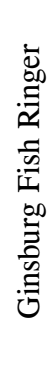 } & \multirow{3}{*}{ 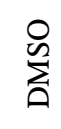 } & $5 \%$ & $81 \pm 2$ & $80 \pm 0$ & $76 \pm 2$ & $73 \pm 1$ & $60 \pm 5$ & $53 \pm 3$ & $38 \pm 2$ & $33 \pm 2$ & $6 \pm 3$ & 0 \\
\hline & & $10 \%$ & $81 \pm 2$ & $78 \pm 2$ & $70 \pm 6$ & $56 \pm 3$ & $38 \pm 2$ & $30 \pm 5$ & $21 \pm 6$ & $6 \pm 3$ & 0 & 0 \\
\hline & & $15 \%$ & $75 \pm 3$ & $76 \pm 2$ & $58 \pm 2$ & $46 \pm 3$ & $28 \pm 2$ & $16 \pm 3$ & 0 & 0 & 0 & 0 \\
\hline & \multirow{6}{*}{ 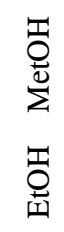 } & $5 \%$ & $86 \pm 1$ & $81 \pm 2$ & $78 \pm 2$ & $71 \pm 1$ & $68 \pm 2$ & $63 \pm 4$ & $55 \pm 5$ & $33 \pm 3$ & $16 \pm 3$ & 0 \\
\hline & & $10 \%$ & $81 \pm 1$ & $78 \pm 2$ & $75 \pm 3$ & $70 \pm 3$ & $65 \pm 3$ & $58 \pm 4$ & $51 \pm 6$ & $13 \pm 3$ & 0 & 0 \\
\hline & & $15 \%$ & $75 \pm 3$ & $68 \pm 2$ & $65 \pm 3$ & $61 \pm 1$ & $48 \pm 2$ & $38 \pm 4$ & $31 \pm 8$ & 0 & 0 & 0 \\
\hline & & $5 \%$ & $83 \pm 2$ & $83 \pm 2$ & $78 \pm 2$ & $73 \pm 2$ & $63 \pm 2$ & $46 \pm 2$ & $21 \pm 2$ & $11 \pm 2$ & 0 & 0 \\
\hline & & $10 \%$ & $83 \pm 2$ & $81 \pm 3$ & $73 \pm 2$ & $68 \pm 2$ & $58 \pm 2$ & $38 \pm 2$ & $15 \pm 3$ & 0 & 0 & 0 \\
\hline & & $15 \%$ & $73 \pm 3$ & $70 \pm 3$ & $66 \pm 3$ & $63 \pm 2$ & $48 \pm 2$ & $13 \pm 2$ & 0 & 0 & 0 & 0 \\
\hline
\end{tabular}


In egg-yolk citrate, $5 \%$ DMSO produced $81 \pm 2 \%$ motility at 5 min incubation which dropped to $76 \pm 2 \%$ at $10 \mathrm{~min}$. DMSO at $10 \%$ concentration produced $78 \pm 2 \%$ motility at $5 \mathrm{~min}$ incubation that reduced to $73 \pm 2 \%$ at 10 min. Similarly, egg-yolk citrate with $5 \%$ methanol produced $81 \pm 2 \%$ motility at $5 \mathrm{~min}$ incubation which reduced to $78 \pm 2 \%$ at $10 \mathrm{~min}$, and $5 \%$ ethanol produced $78 \pm 1 \%$ motility at 5 min incubation which reduced to $76 \pm 2 \%$ at $10 \mathrm{~min}$ incubation (Table I).

In Ginsburg Fish Ringer solution, 5\% DMSO produced $80 \pm 0 \%$ motility at 5 min incubation which reduced to $78 \pm 2 \%$ at $10 \mathrm{~min}$ incubation. DMSO at $10 \%$ concentration produced $78 \pm 2 \%$ motility at $5 \mathrm{~min}$ incubation that reduced to $70 \pm 6$ at $10 \mathrm{~min}$. Methanol (5\%) as cryoprotectant produced $81 \pm 2 \%$ motility at 5 min and $78 \pm 2 \%$ motility at 10 min incubation. Methanol at $10 \%$ concentration produced $78 \pm 2 \%$ motility at 5 min incubation that reduced to $75 \pm 3 \%$ at $10 \mathrm{~min}$ incubation. Similarly, ethanol at $5 \%$ and $10 \%$ concentrations produced $83 \pm 2 \%$ and $81 \pm 3 \%$ motility at 5 min incubation which reduced to $78 \pm 2 \%$ and $73 \pm 2 \%$ at 10 min incubation respectively (Table I). In all the combinations of extenders and cryoprotectants, sperm motility gradually reduced at $15 \%$ concentrations and stopped at $30 \%$ and onwards.

Determination of suitable diluent. This experiment was conducted to screen out suitable extender and cryoprotectant from three extenders (Alsever's solution, egg-yolk citrate and Ginsburg Fish Ringer) and three cryoprotectants (DMSO, methanol and ethanol) for the cryopreservation of spermatozoa. The efficiency of the extenders and cryoprotectants were tested on the basis of sperm motility at the equilibration and post-thaw period. The results showed significant differences $(p<0.01)$ between the equilibration and post-thaw spermatozoan motility for all the combinations of extenders and cryprotectants (Fig. 2). The highest equilibration motility was recorded from Alsever's solution with DMSO $(86.3 \pm 2.04 \%)$, while Ginsburg Fish Ringer combined with DMSO showed second highest equilibration motility $(82.5 \pm 2.04 \%)$. All the three extenders, combined with methanol produced comparatively lower equilibration motility ranged from $73.6 \pm 2.39 \%$ to $80.0 \pm 3.22 \%$ and even more reduction in equilibration motility was occurred with ethanol ranging $66.3 \pm 2.39 \%$ to $68.8 \pm 2.39 \%$.

The highest post-thaw motility was recorded from Alsever's solution with DMSO $(77.5 \pm 3.22 \%)$. Egg-yolk citrate and Ginsburg Fish Ringer along with DMSO produced $63.9 \pm 2.39 \%$ and $62.5 \pm 3.22 \%$ post-thaw motility respectively. Alsever's solution combined with methanol and ethanol produced $67.5 \pm 3.22 \%$ and $47.5 \pm 3.22 \%$ post-thaw motility respectively, where egg-yolk citrate and Ginsburg Fish Ringer along with those cryoprotectants produced $>38 \%$ post-thaw motility (Fig. 2). The ANOVA showed highly significant influences $(p<0.01)$ of all the extenders on equilibration and post-thaw motility of sperm. Similarly, the cryoprotectants had significant $(p<0.01)$ influences on both equilibration and post-thaw motility. Their combinations had also significant effects $(p<0.05)$ on equilibration and postthaw motility of spermatozoa (Fig. 2). The DMRT revealed that Alsever's solution plus DMSO was the best combination for cryopreservation of sperm of $H$. fossilis.

Effects of cryopreserved spermatozoa on fertilization and hatching of eggs. Eggs were fertilized with cryopreserved sperm as well as with fresh sperm. Alsever's solution with both DMSO and methanol produced significantly $(p<0.05)$ lower fertilization $(52.5 \pm 3.34 \%$ and $46.9 \pm 3.11 \%)$ and hatching $(38.0 \pm 2.39 \%$ and $32.7 \pm 2.70 \%)$ than control $(76.1 \pm 5.40 \%$ and $56.7 \pm 4.42 \%)$ 
respectively. On the other hand, an apparently higher percentage of hatching $(38.0 \pm 2.39 \%)$ was observed from Alsever's solution with DMSO than Alsever's solution plus methanol $(32.7 \pm 2.70 \%)$, but no significant difference $(p>0.05)$ was observed between the two diluents (Fig. 3).

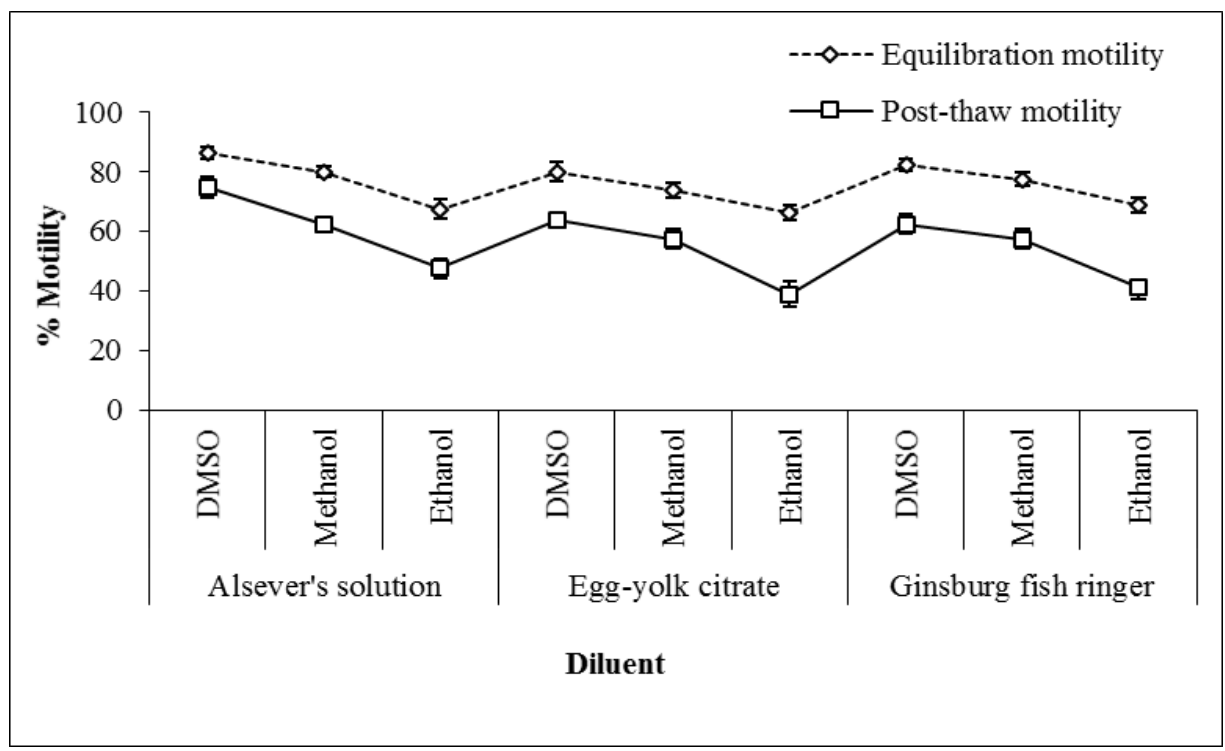

Fig. 2. Equilibration and post-thaw spermatozoan motility of $H$. fossilis at different combinations of extenders and cryoprotectants.

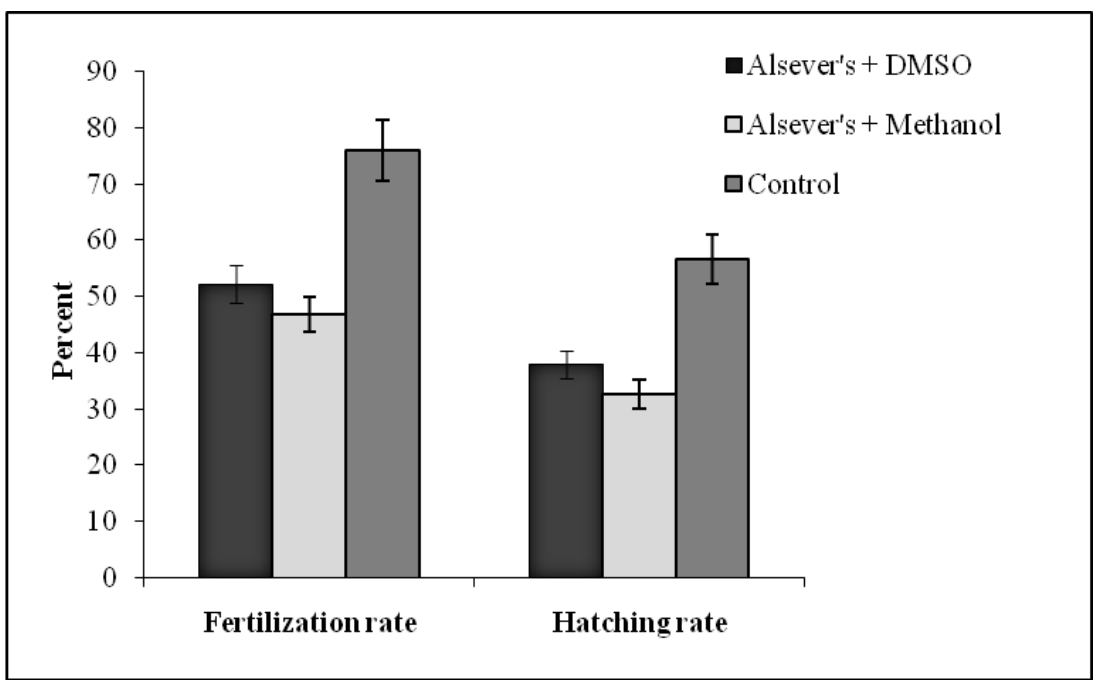

Fig. 3. Fertilization and hatching rates of eggs of $H$. fossilis obtained from cryopreserved and fresh sperm. 
Effects of cryopreservation on the growth and survival of fry: When the data on length and weight of fry produced with cryopreserved sperm and fresh sperm were analyzed, no significant $(p>0.05)$ difference was observed between the two groups. Actually, no major differences in either length or weight were found between the fresh and cryopreserved sperm groups (Fig. 4 and Fig. 5). The survival rate of fry was also determined and a good survival was found for both groups. The cumulative survival rate of control fry was estimated as $85.8 \pm 2.79 \%$ and that of cryopreserved sperm-originated fry was $81.2 \pm 3.27 \%$ (Alsever's solution with DMSO) and $77.9 \pm 3.78 \%$ (Alsever's solution with methanol) during 8 weeks rearing period (Fig. 6). The data on survival rate of fry produced with cryopreserved sperm and fresh sperm were analyzed and no significant $(p>0.05)$ difference was observed among them.

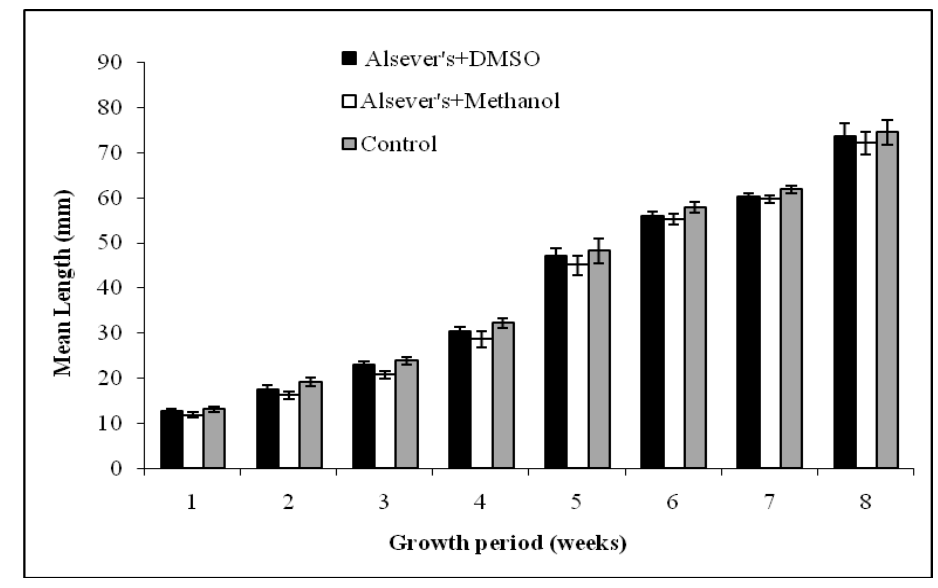

Fig. 4. Length (mm) of $H$. fossilis fry originated from cryopreserved and fresh sperm.

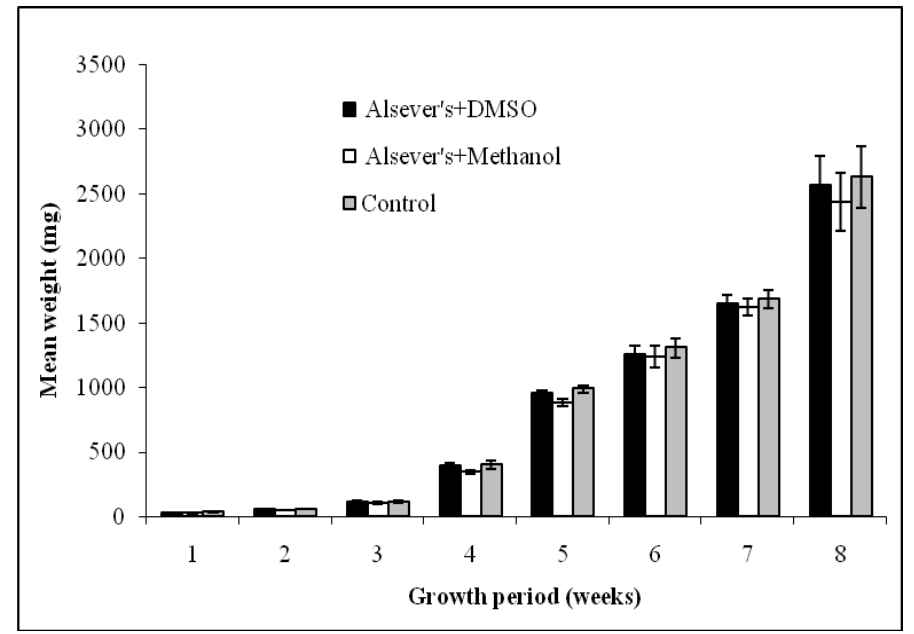

Fig. 5. Weight (mg) of $H$. fossilis fry originated from cryopreserved and fresh sperm. 


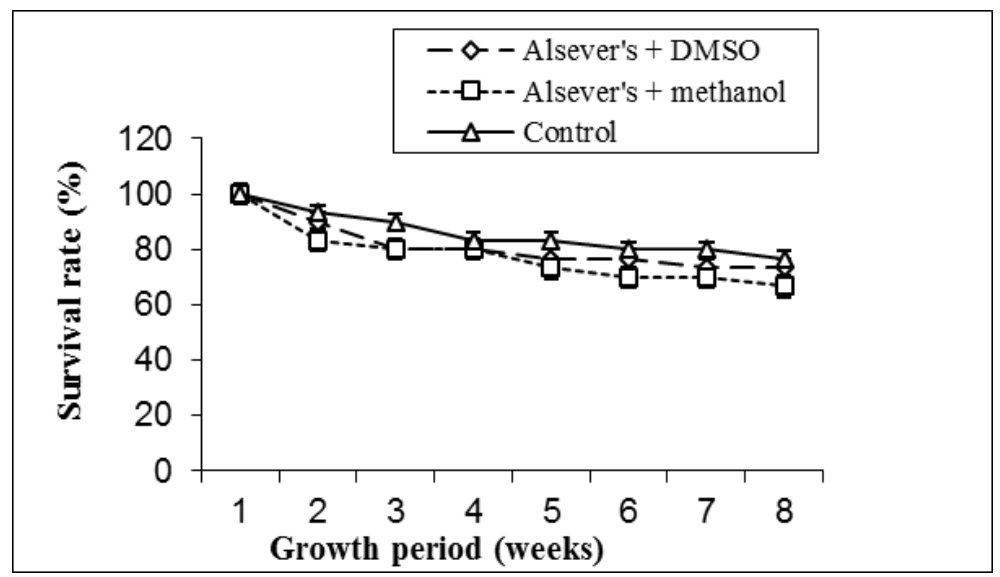

Fig. 6. Survival rate (\%) of $H$. fossilis fry originated from cryopreserved and fresh sperm.

\section{Discussion}

Prior to sperm cryopreservation, it is important to know the sperm activation and motility for formulating suitable extender solution. The extender is a buffer like-solution that usually contain organic or inorganic chemicals and make an artificial medium for survival of the spermatozoa in liquid $\mathrm{N}_{2}\left(-196^{\circ} \mathrm{C}\right)$ through providing the same osmotic pressure that it gets in fresh condition. In this experiment, the activation of sperm of $H$. fossilis suspended with three extenders such as Alsever's solution, egg-yolk citrate and Ginsburg Fish Ringer solution was tested in different concentrations of $\mathrm{NaCl}$ solution and found that the motility of sperm was decreased with the increase of $\mathrm{NaCl}$ concentration. The motility of sperm was $>80 \%$ up to $0.1 \% \mathrm{NaCl}$ solution (48 $\mathrm{mOsmol} / \mathrm{kg}$ ) and it became zero at beyond $0.9 \% \mathrm{NaCl}$ solution $(287 \mathrm{mOsmol} / \mathrm{kg})$. Yang et al. (2007) reported that the activation of sperm motility decreased as the osmotic pressure of Hanks balanced salt solution increased. Alavi and Cosson (2006) reported that the motility of Zebra fish sperm decreased as the osmolality of the extender solution increased, and was completely inhibited at osmolality of $300 \mathrm{mOsmol} / \mathrm{kg}$ and above. Sperm quality is normally evaluated by assessing some parameters such as sperm motility, sperm concentration, volume of milt, morphology of sperm etc. Sperm quality can be varied among males or within the same individual (Rana et al. 1995). There are several factors that affect sperm motility such as $\mathrm{P}^{\mathrm{H}}$, temperature, ions and osmolality (Morisawa et al. 1999, Alavi and Cosson 2006). $\mathrm{P}^{\mathrm{H}}$ has been reported as one of the major sperm activating factors in fish species (Stoss, 1983). Fish sperm are usually immotile in the testis, and motility is controlled by factors such as osmolality, ions, temperature and $\mathrm{P}^{\mathrm{H}}$. Osmolality is the dominant factor in most species studied. In general, motility of sperm from freshwater fish is initiated by hypotonic solutions and motility of sperm from marine fish is initiated by hypertonic solutions (Cosson 2004, Yang et al. 2006).

Cryoprotectant is added to extender to minimize the stress on sperm cells during cooling and freezing and also to protect the cells from cold-shock through external crystal formation or injury. The efficacy of the cryopreservation is greatly increased if the pre-frozen milt is diluted with suitable diluent (extender + cryoprotectant). Though cryoprotectant is essential for preservation, it is also toxic to the cell, so concentration of cryoprotectant needs to be 
optimized. In the toxicity test, three cryoprotectants- DMSO, methanol and ethanol were used with different concentrations and the sperm suspension was incubated with them for a period of 5 to $45 \mathrm{~min}$. In most of the cases $5 \%$ and $10 \%$ concentrations of cryoprotectant produced good motility during 5 and 10 min incubation but $15 \%$ concentration seemed toxic to sperm. DMSO showed better performance at 5\% and $10 \%$ concentration and in some cases 5\% DMSO produced better motility than $10 \%$ concentration. Leung (1987) observed best post-thaw motility of barramundi sperm at 5\% DMSO. Other cryoprotectants, methanol and ethanol showed decreased motility with their increasing concentration (Zhang and Rawson 1995). Cryoprotectant concentration was maintained at $10 \%(\mathrm{v} / \mathrm{v})$ by volume in the present trials as it was reportedly common and effective for many species (Withler and Lim 1982, Shirohara et al. 1982). In this study, motility decreased with the increase of DMSO concentration (more than 10\%) and $15 \%$ DMSO gave least motility. The choice of the cryoprotectants was made on the basis of earlier study conducted by Yang et al. (2007) on Zebra fish.

For cryopreservation of sperm, three extenders such as Alsever's solution, egg-yolk citrate and Ginsburg Fish Ringer solution and three cryoprotectants viz. DMSO, methanol and ethanol were selected based on the outputs of earlier studies of Kumar (1988 and 1989) on Indian major carps and of Linhart and Rodina (2000) on common carp. Among the cryoprotectants, $10 \%$ DMSO with Alsever's solution gave significantly $(p<0.01)$ highest post-thaw motility $(77.5 \pm 3.22 \%)$ compared to other combinations of extender and cryoprotectant. DMSO had a wide spread acceptance for cryopreservation of fish sperm (Stoss 1983, Rana et al. 1995). On the other hand, methanol gave satisfactory level of post-thaw motility with Alsever's solution (Sarder et al. 2012) but its combination with egg-yolk citrate was significantly $(p<0.01)$ lower $(63.8 \pm 2.39 \%)$ than that of previous combination. As an essential component, the choice of cryoprotectants often depends on the ability of their permeation through cell membrane. DMSO, methanol and ethanol as low molecular weight molecules were selected as cryoprotectants with the view that they would pass through the cell membrane easily and minimize the stress on the cells during cooling and freezing. DMSO penetrates rapidly into the cellular membrane (Rao 1989) and brings a quick balance between the intra and extra-cellular fluid concentration.

To examine the effects of cryopreservation on fertilization and hatching, breeding trails were conducted with fresh and cryopreserved sperm. The efficacy of the cryopreserved sperm to fertilize egg is a key indicator in evaluating the success of cryopreservation (Honeyfield and Krise 2000) and fertility of the frozen-thawed sperm is strongly positively correlated with its motility (Magyary et al. 1996). In this study, sperm preserved with Alsever's solution plus DMSO and Alsever's solution with methanol were used for fertilization and their efficacies were compared with control. The fertilization and hatching rates of cryopreserved sperm was satisfactory $(32.7-38.0 \%)$ but significantly $(p<0.05)$ lower than that of control $(56.0-76.1 \%)$. Highest hatching rate $(49.06 \%)$ of eggs of $H$. fossilis fertilized by sperm preserved with Hank's Balanced Salt Solution (HBSS) was reported by Lal et al. (2009). Variation of fertilization and hatching in breeding trials was reported by Rana and McAndrew (1989) where fertilization rates varied from $38.7 \%$ to $93.4 \%$ of control after 13 months of storage of tilapia spermatozoa. Variation in fertilization and hatching of eggs of Ompok pabda and Nandus nandus using cryopreserved sperm was also reported by Sarder et al. $(2012,2013)$. 
After producing fry using cryopreserved sperm, it was important to know the growth and survival of fry. Fry of both cryopreserved and fresh sperm origin were reared in controlled environment for eight weeks and no significant $(p>0.05)$ growth difference was found between two groups. Chao et al. (1987) reported that tilapia Oreochromis hornorum juveniles from thawed sperm grew as well as the control group. Moczarski (1977) found no decrease in survival rates with 1-year old carp (Cyprinus carpio L.) juvenile from thawed sperm. Tiersch et al. (1994) found no growth differences of channel catfish at any age 2-12 months between offspring produced with cryopreserved sperm or untreated sperm. Similar results were obtained for common carp through comparing the growth performance of fry produced with cryopreserved and fresh sperm (Sarder et al. 2007). In contrast, Van Der Walt et al.(1993) obtained significant differences in African catfish, Clarias gariepinus between mean length and weight in some groups at 30,60 and 90 days those obtained from cryopreserved sperm being lower and they assumed that these differences might be attributed to variable environmental conditions encountered from tank to tank.

\section{Conclusions}

The cryopreservation protocol for sperm of $H$. fossilis has been developed through this study and the important components of the protocol such as suitable activation solution, toxicity level of cryoprotectants and suitable combination of diluents were standardized. Fertilization of eggs using cryopreserved sperm was possible and it was closed to control but significantly lower hatching was obtained by cryopreserved sperm which need to be improved. Growth of fry produced with cryopreserved sperm was more or less similar to those produced with fresh sperm, so there was no negative impact of cryopreservation on sperm and the technology could be used in commercial hatcheries.

\section{Literature cited}

Alavi, S.M.H and J. Cosson, 2006. Sperm motility in fishes. II. Effects of ions and osmolality: a review. Cell Biol. Int., 30: 1-14.

Chao, N.H., W.C. Chao, K.C. Lui, and I.C. Liao, 1987. The properties of tilapia sperm and its cryopreservation. Fish Biol., 30: 107-118.

Cosson, J., 2004. The ionic and osmotic factors controlling motility of fish spermatozoa. Aquac. Int., 12: 69-85.

Honeyfield, D.C. and W.F. Krise, 2000. Measurement of milt quality and factors affecting viability of fish spermatozoa. In: T.R. Tiersch and P.M. Mazik (eds.), Cryopreservation in Aquatic species, World Aquaculture Society, Baton Rouge, Louisiana, USA. 49-58.

Hossain, M.A., A.H. Rahman, S. Parween, and M.A. Rahman, 1994. Fish stock assessment and utilization of seasonal ditches. J. Ecobiol., 6: 61-66.

Islam, M.A. 1989. Nana deshe machher chash. Bangla Academy, Dhaka. 105-121.

Kumar, K., 1988. A comparative study of various extenders for cryopreservation of carp sepermatozoa. Indian Anim. Sci., 58(11): 1355-1360.

Kumar, K. 1989. Studies on cryogenic preservation of carp spermatozoa In: Das and Jhingran (eds.) Fish Genetics in India, Today and Tomorrows Printers and Publishers, New Delhi. 199-206.

Lal, K.K., A.S. Barman, P. Punia, P. Khare, V. Mohindra, B. Lal, A. Gopalakrishnan, R.S. Sah and W.S. Lakra, 2009. Effect of extender composition on sperm cryopreservation of Asian catfish Heteropneustes fossilis (Bloch) and Clarias batrachus (Linnaeus). Asian Fish. Sci., 22: 137-142. 


\section{RAFIQUL ISLAM SARDER et al.}

Leung, L.K.P., 1987. Cryopreservation of spermatozoa of the barramundi, Lates calcarifer (Teleostei: Centropomidae). Aquaculture, 64: 243-247.

Linhart, O. and M. Rodina, 2000. Cryopreservation of common carp (Cyprinus carpio) and Tench (Tinca tinca) sperm for gene resources conservation. Reprod. Physiol. Fish. 23: 402-404.

Magyary, I., B. Urbanyi, and L. Horvath, 1996. Cryopreservation of common carp (Cyprinus carpio L.) sperm: II. Optimal conditions for fertilization. J. Appl. Ichthyol., 12: 117-119.

Moczarski, M. 1977. Deep freezing of carp Cyprinus carpio L. sperm. Biol. Bull. Acad. Sci., USSR, 25 (3): $187-190$.

Morisawa, M., T. Hirano and K. Suzuki, 1999. Changes in blood seminal plasma composition of the mature salmpon (Oncorhynchus keta) during adaptation to freshwater. Comp. Biochem. Physiol., 64: 325-329.

Rana, K. J. and B.J. McAndrew, 1989. The viability of cryopreserved Tilapia spermatozoa. Aquaculture 76: $335-345$.

Rana, K.J., S. Edwards and R. Shield. 1995. Potential application of low temperature preservation of Atlantic halibut (Hippoglossus hippoglossus L.) and salmon (Salmo salar) spermatozoa for seed production. In: Proc. of Fish \& Shellfish Larval Aquaculture Symposium. P. Lavens, E. Jaspers and I. Roelants (eds.). 53-56.

Rao, K.G. 1989. Cryopreservation of carp sperm. In: Das and Jhingran (eds.) Fish Genetics in India, Today and Tomorrows Printers and Publishers, New Delhi. 193-198.

Sarder, M.R.I., M.S. Hossain, M.M. Al- Mamun and M.H.O. Rashid, 2007.Growth and survival of fry of common carp (Cyprinus carpio) produced with cryopreserved sperm. The Bangla. Vet. 24(1): 7986.

Sarder, M.R.I., M.F.M. Sarker and S.K. Saha. 2012. Cryopreservation of sperm of an indigenous endangered fish species Nandus nandus (Hamilton 1822) for ex-situ conservation. Cryobiology, 65: 202-209.

Sarder, M.R.I., S.K. Saha and M.F.M. Sarker, 2013. Cryopreservation of sperm of an indigenous endangered fish, Pabda Catfish Ompok pabda. North American J. Aquacult., 75: 114-123.

Shirohara, J., T. Canto (Jr.) and J. M. F. Rlmendras, 1982. A comparative study of various extenders for milk fish, Chanos chanos (Forssakal) sperm preservation. Aquaculture, 28: 339-346.

Srivastava, C.B.L. 1988. A text book of fishery science and Indian fisheries. Vol. II, KitabMahal, Alahabad, India. 307 p.

Stoss, J., 1983. Fish gamete preservation and spermatozoa physiology. In: Fish Physiology, Volume 9B. W.S. Hoar, D.J. Randall and E.M. Donaldson (eds.), Academic press, New York. 305-350.

Tiersch, T.R., C.A. Goudie and G.J. Carmichael, 1994. Cryopreservation of channel catfish sperm: cryoprotectants, fertilization trials and growth of channel catfish produced with cryopreserved sperm. Trans. Amer. Fish. Soc., 123: 580-586.

Van Der Walt, L.D., F.H. Van der Bank and G.J. Steyn, 1993. The suitability of using cryopreservation of genetic diversity in African catfish (Clarias gariepinus). Comp. Biochem. Physiol. 106A, 313-318.

Withler, F.C. and L.C. Lim, 1982. Preliminary observations of chilled and deep-frozen storage of grouper (Epinephelus tauvina) sperm. Aquaculture, 27: 389-392.

Yang, H., C. Carmichael, Z.M. Varga and T.R. Tiersch, 2007. Development of a simplified and standardized protocol with potential for high-throughput for sperm cryopreservation in Zebrafish Daniorerio. Theriogenology, 68: 128-136.

Yang, H., L. Hazlewood, R.B. Walter and T.R. Tiersch, 2006. Effect of osmotic immobilization on refrigerated storage and cryopreservation of sperm from a viviparous fish, the Green Swordtail Xiphophorus helleri. Cryobiology, 52: 209-218.

Zhang, T. and D.M. Rawson, 1995. Studies of chilling sensitivity of zebra fish (Brachydanio rerio) embryos. Cryobiology, 32: 239- 246.

(Manuscript received: 6 April 2020) 